\title{
The Juazeiro (Ziziphus Joazeiro Mart.) and the Formation of Concepts and Parameters in Chemical Technology Education
}

\author{
José Carlos Oliveira Santos ${ }^{1, *}$, Ana Paula da Costa ${ }^{1}$, Aline de Lima Araújo ${ }^{1}$, Jakeline Santos Martins ${ }^{1}$, Lioran \\ Fagner Bento de Oliveira ${ }^{1}$, Vagner Cunha Lima ${ }^{1}$, Romário Jonas de Oliveira ${ }^{1}$, Danilo Lima Dantas ${ }^{1}$ and Frank \\ Madson Araújo Melo ${ }^{2}$ \\ ${ }^{1}$ Academic Department of Biology and Chemistry \\ Centro de Educação e Saúde, Universidade Federal de Campina Grande - UFCG \\ Cuité, Paraíba, 58175-000, Brazil.
}

${ }^{2}$ State Preparatory Innovative High School Professor Lordão

Picuí, Paraíba, 58187-000, Brazil.

*Corresponding author's email: zecarlosufcg [AT] gmail.com

\begin{abstract}
Ranging from the northeast of Brazil to the north of Minas Gerais, in the region of the savanna, the popularly known Juazeiro (Ziziphus Joazeiro Mart.) is a plant that has great potential medicinal, scientific and economic that can be used in order to contextualize the chemistry teaching that increasingly is becoming fragmented and full of gaps. The aim of this study is to suggest possible concepts and chemistry discipline of content that can be worked by analyzing the properties and benefits of Ziziphus Joazeiro. There are many chemical concepts that can be worked through juazeiro. In this paper we present some of them such as polarity of the molecules, hydrophilic and hydrophobic substances, antioxidants, solubility, and others that can be studied. It is of great importance the study of plants of a region so threatened as the savanna. This study was the starting so that teachers start to change their way of teaching and find ways to enable student learning takes place in a positive and satisfactory.
\end{abstract}

Keywords-Ziziphus Joazeiro; Experimentation; Contextualization; Chemistry education

\section{INTRODUCTION}

The greatest difficulties for students to learn chemistry are demonstrated in various levels of education, because students not realize the validity and significance of studying. This is often due to inadequate contextualization of content with the reality experienced by the student, not so arousing the interest and motivation of the same discipline [1,2].

Often teachers are trapped only the information in the textbook and lead the class in a traditional way without any context. This is due to the fact that teachers do not have time, since the low remuneration do they have to work in more than one school, thus, with a very high workload which not of to fit a schedule to better plan its teaching methodology [3]. Another major problem is the lack of commitment of both students who do not want to quit to study as well as some teachers who stop in time and do not seek to improve their teaching practice, even having enough time and materials available to perform such a task.

Thus student understanding about the chemistry teaching gets complicated, because it is being done in a piecemeal fashion leaving many gaps and it is hoped that one day the student gather all these fragments and fill all these gaps thus ensuring learning like a quick and easy task. We know that following this path the student will never understand the concepts of chemistry and science but also learn to relate them to their daily lives and the day to day [4].

The study of brazilian regional plants has been highlighted in recent years $[4,5,6]$. A form of solution to facilitate students' understanding about chemical concepts is your relationship with facts and things in their environment, that is, he knows things like water, food, plants and more. A very important and that has this ability to be profitably studied by the chemical plant is the Juazeiro (Ziziphus Joazeiro Mart.), kind of great potential of the Brazilian savanna, which occurs from the northeast to the north of Minas Gerais state, with large economic, ecological and medicinal, from the production of firewood and charcoal to treat disease.

A form of solution to facilitate students' understanding about chemical concepts is your relationship with facts and things in their environment, that is, he knows things like water, food, plants and more. A very important and it has this ability to be studied profitably by the chemical plant is the Juazeiro (Ziziphus Joazeiro Mart.) species of great potential of 
the savanna, which occurs from the Brazilian northeast to the north of Minas Gerais, with large economic, ecological and medicinal, from the production of firewood and charcoal to treat disease. It is also used in cosmetics and oral hygiene due to the presence of saponins in its chemical composition $[4,7]$.

Following the line of thinking in seeking new ways to contextualize the chemical knowledge and as well as value species typical of dry climates that are not so utilized the objective of this study is to suggest possible concepts and chemistry discipline of content that can be worked through analysis of the properties and benefits of Ziziphus Joazeiro [3]. Encouraging in this way the teachers who feel interested in change for the better or else add new ways of teaching methodologies of chemical technology content in the classroom making it more attractive and diverse class.

\section{MATERIAL AND METHODS}

This study was conducted at the State Preparatory High School Innovative Professor Lordão, located in the urban area of Picuí municipality in the state of Paraíba, Brazil, with an implementation period occurred between May and July of this year. The target audience of the research was students of class of third year of regular high school.

The aim of this study was to suggest possible concepts and chemistry discipline of content that can be worked by analyzing the properties and benefits of Ziziphus Joazeiro. The bibliographic review of the plant properties and their uses can be studied. There are many chemical concepts that can be worked through juazeiro, in this paper we present some of them such as polarity of the molecules, hydrophilic and hydrophobic substances, antioxidants, solubility, and others that can be studied.

Experiments and activities were carried out in chemistry classrooms that have led to the incorporation of this plant in the formulation of chemical technology concepts.

\section{RESULTS AND DISCUSSION}

\subsection{Description of Ziziphus Joazeiro}

The Juazeiro (Ziziphus Joazeiro Mart.) is one of the promising species of the savanna (Biome threatened in Brazil) and its use in shampoos and other related products due to the presence of saponins in various parts of the plant [8]. Saponin comes from the Latin sapo meaning soap, therefore, foams when extracts rich in this substance are stirred in water [9].

The juazeiro occurs from the northeast to the north of Minas Gerais, Brazil. It presents great economic and ecological importance, which is used locally for production of firewood and charcoal, afforestation of streets and gardens, and has edible fruit. It is also used in folk medicine as an expectorant to treat bronchitis and gastric ulcers, in the manufacture of cosmetics as well as serving in animal feeding mainly in the dry season [10].

According to Silva et al. [10], the plant has use as a mouthwash against skin disorders such as wound healing and the chips reduced to powder stem, can be used as toothpaste. Still analyzing Silva work it was revealed that the Juazeiro has substances with antioxidant activity, i.e., substances that hinder or substantially prevent the oxidation of lipids or other molecules to inhibit the initiation and / or propagation of the chain oxidation reaction yet capture free radicals, which may not be in high amounts in the body, therefore their presence has been correlated with a number of diseases, not having etiologic role in most pathological states but who participate directly in the pathophysiological mechanisms determining the continuity and complications present in these processes. Figures 1 and 2 below show the plant's bark shavings and his fruit still not harvested respectively.

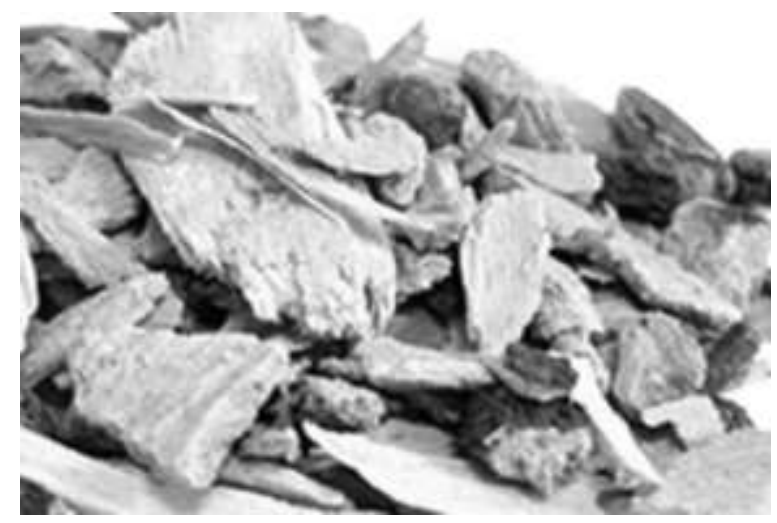

Figure 1: Image of stem clothes of Ziziphus Joazeiro 


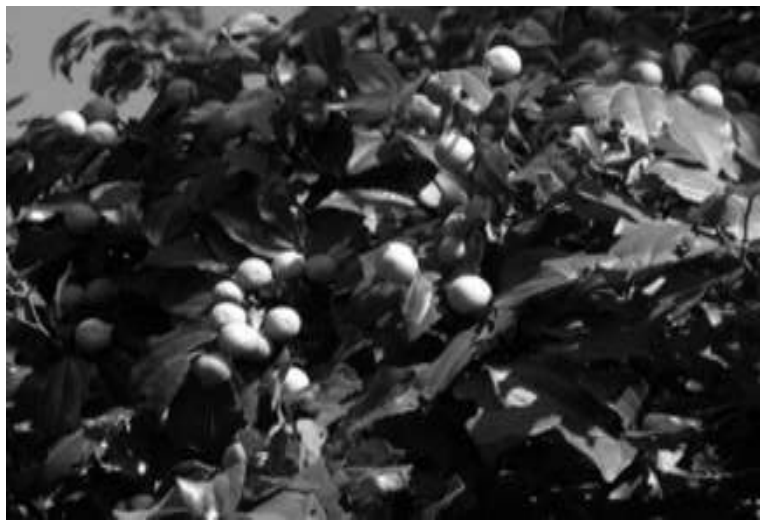

Figure 2: Image of the fruits of Ziziphus Joazeiro

\subsection{Chemical technology contents to be addressed through Ziziphus juazeiro}

There are several possibilities to enjoy the Ziziphus Joazeiro chemically. As previously mentioned this plant has saponins in its chemical composition. Saponin is a substance that has a hydrophobic part and hydrophilic part of the molecule, or is parts which respectively have no affinity for water and parts which have this affinity.

As with the analysis of this information the teacher can work with some chemical concepts such as molecular polarity, since the saponin has a polar part and apolar substances solubility in water and affinity substances with a fat and water.

Another possibility is to study the chemical composition of the plant, since it not only has a saponin, but many other substances and also the composition of the soil where the plant is located.

The jujube has substances with antioxidant activity, knowing that the teacher can use this information in the study of organic chemistry and relate to the content of organic reactions addressing the capture of free radicals very important process in our body that is able to prevent some diseases and premature aging.

After the analysis was highlighted by the high school students that, among the applications of ziziphus joazeiro in chemical technology, wood stands out, which can be used in joinery, coffins, internal doors, rural constructions, carpentry and wood and charcoal. Wood is also used as firewood producing the best ash for the manufacture of earth soap as it is very rich in potash. Forage fruits, leaves and branches are fodder for cattle, goats and pigs. Juazeiro's hay is well consumed by animals. The juazeiro power used in feeding goats and sheep as an alternative food resource during the dry season. The ripe fruit, rich in vitamin $\mathrm{C}$, is good food for man, also looking for animals. The branch and the fruits serve as food for all animals, but are also consumed by the poor population. In medicine, the infusion of the leaves is stomach and the water of the fruit serves to soften and to lighten the skin. The barks are bitter, astringent, useful in the diseases of the skin and also employed as hair tonic. Medicinal use as hair tonic, tooth cleaning agent, hair cleaning. Rasp tea is advantageously applied to bruises, blows and wounds, also used to wash wounds and, in compresses, relieve bruises. The scraper is used for washing dishes, glasses and household utensils. Due to its high content of saponin, the bark, in the form of powder, is used by the poor caatinga population as a substitute for shampoo, soap, soap and toothpaste. Among other technological applications, the following are noteworthy: the peeled raspberries are rich in saponin, they serve as soap and dentifrice. The bark is excellent hair tonic when infused or macerated. The ash of the wood, rich in potash is much used for bleaching in the manufacture of soap, even industrially. The tree provides good shade, besides having ornamental quality.

\subsection{Applications in Chemistry Classrooms}

During the enforcement activities, the first step was a minicourse in relation to the chemistry of the third year of high school content specifying the glycoside molecules that can be classified as carbohydrates [11].

The short course was to benchmark the content of organic functions present in saponin molecules. Saponins are glycosides which are present in the plant metabolism. The saponin glycosides have this classification because they form foam when shaken with water. This sparkling property present in Juá is the main substance for artisanal manufacture of toothpaste. Figure 3 shows students attending a class on the Juá and chemical content. In this first stage of the project, the teacher should encourage the knowledge of the student about the proper subject with the aim of bringing the prior knowledge of the student about the culture, which in our case was the homemade toothpaste made from Juá with the discipline of Chemistry. 


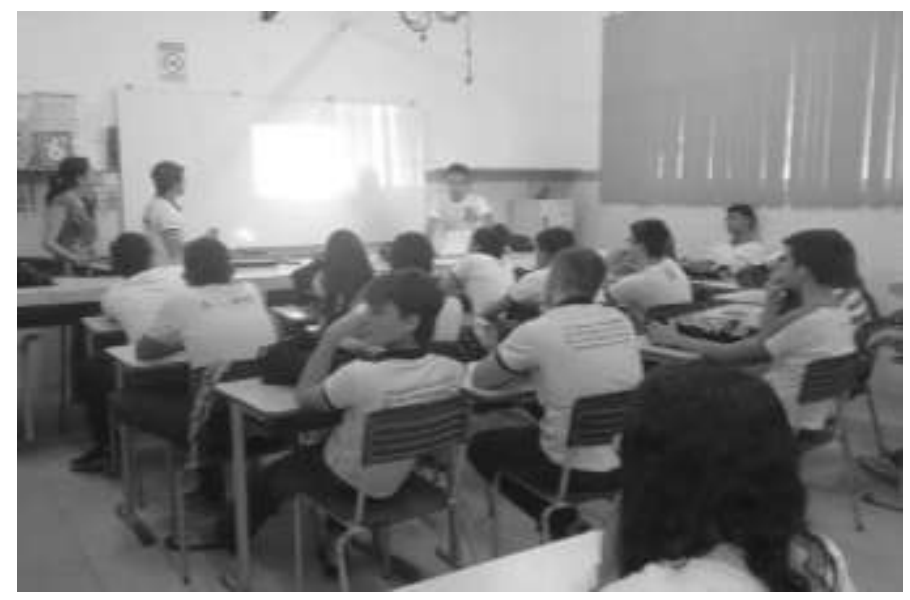

Figure 3: Presentation of short course in relation to chemical contents and Juazeiro

In the second stage of labor, the manufacture of toothpaste derived from Juá was held. The toothpaste can be made as follows: two tablespoons zest of Juá, i.e. the shell of Juá, two tablespoons of dried mint soup, two tablespoons of flax seeds soup three dianthus seeds, a pinch of ground cinnamon, a cup of filtered water. The preparation was performed as follows: the flax was taken to mint and cloves for cooking along with the water over low heat for five minutes. Consecutively, the Juá was added and mixed well, and cinnamon as illustrated in Figure 4.
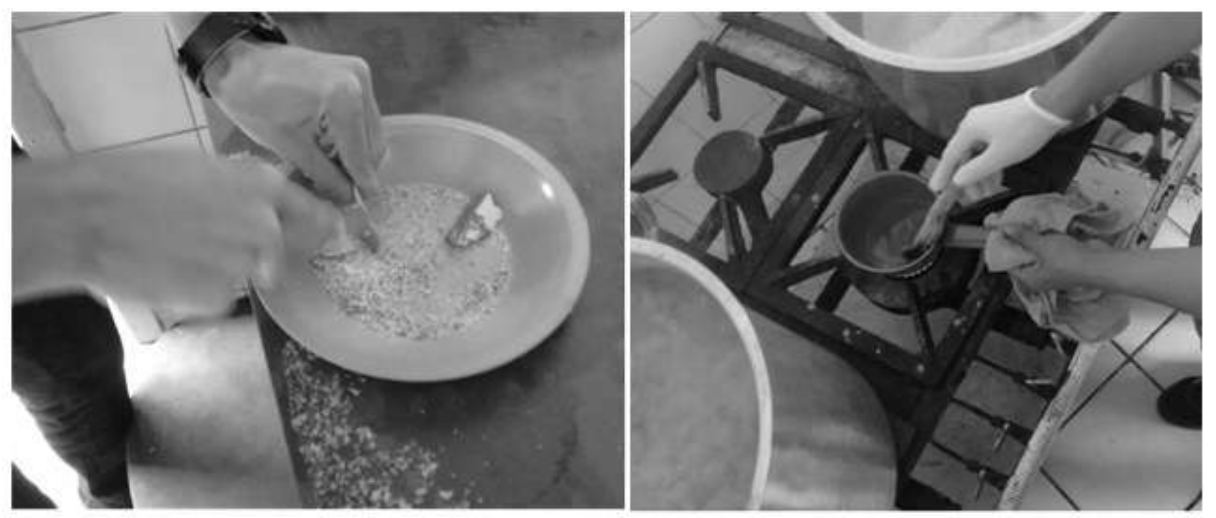

Figure 4: The Juazeiro bark peeling and preparation of toothpaste derived from Juazeiro

During the experimental procedure, the broth with ingredients that are on low heat starts getting denser. Thus, we removed the fire, the broth and place in a closed container. Just then the toothpaste, which was preparing the broth, is ready for consumption. It was applied a small amount of the toothbrush and brushed normally. In a closed container, the toothpaste can be kept for two months.

To check the job objective, in the third stage of the work was the application of a questionnaire regarding visas and syllabus in the classroom. The questionnaire had improved indicator feature in learning [12]. Its composition was ten multiple choice questions regarding the contents seen in the short course and experimental practice for toothpaste made from Juá.

In the classroom were present 40 students who attended the 3 rd year of high school. The evaluation, i.e. each questionnaire used had a maximum average of 10 points. During the assessment there was a result 35 students were average above 7.0. And only five students were average below 7.0. Thus presented an outcome where $75 \%$ of the questionnaires averaged above 7.0 (Concept A and B). In questionnaires fix only 5 students failed to achieve the average 7.0 .

The construction of knowledge of the students, the teacher must motivate their students with some teaching strategies in order to cause some stimulation in relation to content covered in class $[13,14,15,16]$. The results shown by learning improvement indicator, the questionnaire, the Chemistry teaching geared to a student's culture can be applied and an alternative education that seeks not only the understanding of the syllabus, but the relationship of science and the day-today student. Survey data show that $87.5 \%$ of the evaluated questionnaires showed an average 7.0, i.e. a perspective that shows the relationship of the student's culture and chemistry teaching is an alternative for improving learning in the discipline. 


\section{CONCLUSION}

The chemistry teaching requires commitment and the search for new methodologies is one of the functions of the teachers of this science. We cannot let students learn from forced and decorated form, there must be context and studies like this work shows that it is possible to at least be able to relate content with everyday things of each student.

It is the creativity and efforts of each faculty seek to improve their practice. The analysis of the properties of a plant such as Ziziphus Joazeiro and its relationship with some chemical technology concepts is a match for the change in the way of teaching and ensure satisfactory results of hearing students in the classroom.

\section{ACKNOWLEDGEMENT}

The authors thank PIBID / CAPES / UFCG and the Government of Brazil for financial support.

\section{REFERENCES}

[1] Dantas D. L., Silva A. P. F., Santos F. A. C., Santos J. C. O., As Principais Abordagens da Temática Meio Ambiente no Ensino de Química, Blucher Chemistry Proceedings, vol. 3, no. 1, pp. 43-48, 2015.

[2] Santos J. C. O., Costa E. O., Lima R. C. S. L., Araújo D. S., Sousa A. S., Alternative ways in chemistry teaching: Providing the creativity of high school students, Acad. J. Educ. Res., vol. 4, no. 4, pp. 069-074, 2016.

[3] Oliveira R. J., Santos J. C. O., O Juazeiro e a Geração de Conceitos Químicos, Blucher Chemistry Proceedings, vol. 3, no. 1, pp. 23-28, 2015.

[4] Costa A. P., Santos J. C. O., Contextualizando a Química: O Uso de Plantas Regionais na Contextualização de Conceitos Químicos, Blucher Chemistry Proceedings, vol. 3, no. 1, pp. 35-37, 2015.

[5] Santos J. C. O., Physico-Chemical and Thermal Analysis of the Favelone and By-Products (Cnidoscolus phyllacanthus), Research Journal of Agronomy, vol. 1, no. 1, pp. 18-21, 2007.

[6] Santos J. C. O., de Costa A. P., Araújo A. L., Martins J. S., Chemistry and Sustainable Development: The Use of Brazilian Regional Plants in the Context of Chemical Concepts, Acad. J. Sci. Res., vol. 4, no. 9, pp. 276-278, 2016.

[7] Santos J. C. O., Thermal Characterization of the Favelone Oil (Cnidoscolus phyllacanthus), Journal of Food Technology, vol. 5, no. 1, pp. 77-78, 2007.

[8] Oliveira A. K., Coelho M. F. B., Maia S. S., Diogenes F. E. P., Filho S. M., Atividade Alelopática de Extratos de Diferentes Partes de Juazeiro (Ziziphus Joazeiro Mart. - Rhamnaceae), Acta Brasílica, vol. 26, no. 3, pp. 43-49, 2012.

[9] Ribeiro B. D., Alviano D. S., Barreto D. W., Coelho M. A., Functional Properties of Saponins from Sisal (Agave sisalana) and juá (Ziziphus joazeiro): Critical Micellar Concentration, Antioxidant Andantimicrobial Activities, Colloids and Surfaces A: Physicochemical and Engineering Aspects, vol. 43, no. 6, pp. 123-132, 2013.

[10] Silva T. C. L., Almeida C. C. B. R., Veras Filho J., Peixoto Sobrinho T. J. S., Amorim E. L. C., Costa E. P., Araújo J. A., Atividades Antioxidante e Antimicrobiana de Ziziphus Joazeiro Mart. (Rhamnaceae): Avaliação Comparativa entre Cascas e Folhas, Revista de Ciências Farmacêuticas Básica e Aplicada, vol. 32, no. 2, pp. 34-42, 2010.

[11] Lima J. F. L., Pina M. S. L., Barbosa R. M. N., Jófoli Z. M. S., A contextualização no Ensino de Cinética Química, Química Nova da Escola, vol. 11, no. 2, pp. 26-29, 2000.

[12] Subramanian, M., Gore, C. A., An Interventional Study on Change in the Knowledge of High School Students Regarding Ill Effects of Tobacco Use, Asian Journal of Applied Sciences, vol. 1, no. 4, pp. 119-122, 2016.

[13] Cunha M. B., Jogos no ensino de química: Considerações teóricas para sua utilização em sala de aula, Química Nova na Escola, vol. 34, no. 2, pp. 92-98, 2012.

[14] Santos J. C. O., Oliveira L. F. B., Lima V. C., Oliveira R. J., Melo F. M. A., Chemistry of Cosmetics: Using Contextualization and Interdisciplinarity as allowance for Chemistry Teaching, Acad. J. Educ. Res., vol. 4, no. 11, pp. 171-174, 2016.

[15] Silva A. S., Silva R. J. D., Oliveira Junior J. C., Santos J. C. O., An Experimental Approach to Chemistry Teaching: Oxygenated Organic Function Identification Tests on Cosmetics, Acad. J. Sci. Res., vol. 4, no. 3, pp. 069-074, 2016.

[16] Sousa A. S., Silva A. S., Araújo D. S., Silva R. J. D., Costa E. O., Lima R. C. S., Oliveira Junior J. C., Paula J. C. F., Santos J. C. O., O Pibid Contextualizando o Ensino de Química Através do Teatro, Química: ciência, tecnologia e sociedade, vol. 4, no. 2, pp. 71-80, 2015. 